\title{
A Review of Image Registration Methods in Medical Im- aging
}

\author{
Leeba John \\ Dept of ICT \\ Veer Narmad South Gujarat University, Surat, Gujarat, \\ India
}

\author{
Lissa John \\ Dept of ICT \\ Veer Narmad South Gujarat \\ University, Surat, Gujarat, India
}

\begin{abstract}
Image registration is the series of methods which superimposes or aligns two or more images of the same picture taken at different instance of time or moment, from different perspective or angle, and/or by different sensors or any external device. Registration makes the pixels in two images precisely coincide to the same points in the scene. After registration of the images, it can be combined or fused in a way that improves information extraction. Image registration combines two images, i.e., reference image and sensed image, geometrically. There are different approaches of image registration and these approaches are categorized according to their nature that is area based and feature based. Essential steps in Image Registration are feature detection, feature matching, transform model estimation, and image resampling and transformation. This paper focuses on an analysis on Image Registration methods. A literature survey of different research of Medical Image Registration is also presented here. Medical Imaging plays a significant role in medical diagnosis and treatment. It provides a clear view for medical experts in taking the correct decisions on patient's condition. By combining more than one image obtained from different medical imaging modalities, experts can achieve better image visualization for different human anatomy. The aim of this paper is to provide a source for the researchers involved in Image Registration as well as Medical Image Fusion used in diverse applications.
\end{abstract}

\section{Keywords}

Image Registration; Feature Detection; Feature Matching; Transform Model Estimation; Resampling; Transformation; Medical Imaging; Medical Image Modalities.

\section{INTRODUCTION}

Image Registration is an image processing technique in which images can be combined or fused in a way that improves information extraction. It makes the pixels in two images specifically relate to the same points in the scene. Therefore it also helps to align multiple scenes into a single integrated homogeneous image. It is also thought of as a process of superimposing or aligning of more than two images of the same picture taken at different instance of time or moment, from different perspective or angle, and/or by different sensors or any external device. It overcomes issues such as image rotation, scaling, and skewing which are common when superimposing images. The goal of image registration is to align images spatially to minimize a desired error with respect to each other. The input for this process is two images: the original image is known as the reference image while the image that will be aligned with the reference image is known as the sensed image. It produces more useful and better vivid images based on the input ones as shown in Fig 1. Essential steps in Image Registration are feature detection, feature matching, transform model estimation, and image resampling and transformation.
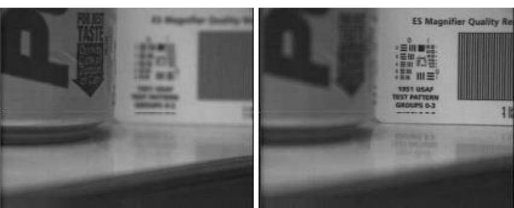

(a) Image 1 (Focus on left)

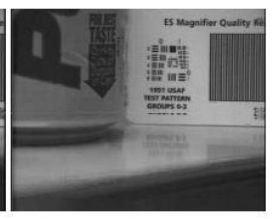

(c) Fused Image (All focus)
Fig 1: Fusion result for multi-focus images

The Application of Image Registration can be arranged into the following categories as discussed below:

\section{i.Various Perspective/Angle (Multi-view Scene}

Analysis): From multiple perspectives, the images captured of the same object or views are taken into consideration for better representation of the scanned object.

Examples: Image Mosaicing (Panorama view), gesture analysis, face detection etc.

ii. Various Time/Moment (Multi-temporal Sequential

Analysis): At various instance of time / period, images taken of the same object or scene under different circumstances to monitor changes are taken into consideration.

Examples: climate change, biodiversity, agriculture, forestry, monitoring of tumor evolution.

\section{iii. Various Sensor/Spectral (Multi-modal Spectral}

Analysis): Acquiring the images captured from various sensors of the same object or scene is considered to obtain the minutiae of the scanned object.

Examples: In the field of Medical Imaging the capturing of anatomical information with the combination of sensors like magnetic resonance image (MRI), Ultrasound or CT, positron emission tomography (PET), single photon emission computed tomography (SPECT) analyzes seizure disorders, Alzheimer's disease and other diseases [1 - 6].

As shown in Fig. 2, Image A and Image B are combined to produce a fused image of higher resolution with a better vision. 


\begin{tabular}{|c|c|c|c|}
\hline Category & Image A & Image B & Fused Image \\
\hline $\begin{array}{c}\text { Multi View } \\
\text { Scene } \\
\text { Analysis }\end{array}$ & & \\
\hline $\begin{array}{c}\text { Multi Tem- } \\
\text { poral Se- } \\
\text { quential } \\
\text { Analysis }\end{array}$ \\
\hline $\begin{array}{c}\text { Multi Mod- } \\
\text { al Spectral } \\
\text { Analysis }\end{array}$
\end{tabular}

Fig 2: Examples of different Image Registration Categories

\section{CLASSIFICATION OF IMAGE REG- ISTRATION METHODOLOGY}

Image Registration is a highly vibrant area due to its broad range applicability in remote sensing for weather forecasting, fusion of medical images which are taken from different medical imaging modalities like CT-MRI, PET-MRI etc. Image Registration Methodology and steps are discussed here. According to Barbara Zitova and Jan Flusser [7] the field of Image Registration can be categorized into two groups: area based methods and feature based methods. Area based methods are used for comparing a pixel in the sensed image to that of the referenced image. It basically uses gray value of the pixels to describe matching entities. On the other side Feature based methods does not uses gray value to describe matching entities, instead it uses image features derived by feature extraction algorithm to find the corresponding pairs. Features such as edges, surfaces, corners, point of intersection, contours etc, which carries relevant information about images used for matching. Majority of the registration methods consist of following four basic steps [8]:

i. Feature Detection: In this step, the significant and appropriate features like Regions, Edges, Corners, etc are identified in both reference image and sensed image automatically or manually by various domain professionals. The above detected features are also known as Control Points Set.

ii. Feature Matching: The mapping of features in the reference and sensed image are considered. Matching method is selected on the basis of image content or the Control Points Set.

iii. Transform Model Estimation: It is one of the crucial steps where once the selected features are extracted with reference to the position of the sensed image and reference image, the parameters and the type of the transformation is estimated. Some of the transformation functions which can be applied are linear, affine, projective etc.

iv. Image Resampling and Transformation: Once the transformation is estimated, the sensed image is transformed and then is resampled using interpolation techniques.

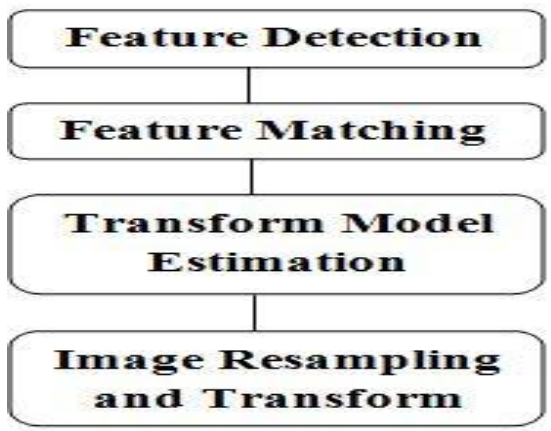

Fig 3: Steps in Image Registration Process

\section{VARIOUS IMAGE REGISTRATION METHODS}

\subsection{Extrinsic Methods}

In this method external objects or markers are used in the patient body [9-12] to be registered. The goal of this method is to obtain more effectiveness, correctness, consistency, high computational speed by evaluating their matching features as it does not need complex algorithm for implementation. It is used in brain image registration skin markers or stereo-tactic frames are used.

\subsection{Moments and Principle Axes Methods}

Principal Axes Registration (PAR) is used for global matching of binary volumes from CT, MR or PET images. The inertia is diagonal when computed with respect to principal axes. The centroid and principal axes can describe the orientation of a volume. The principal axes registration can resolve six degrees of freedom of an object (three rotations and three translations). It can compare the orientations of two binary volumes through rotation, translation and scaling [13]. In moment based methods pre - segmentation is done to obtain satisfactory results.

\subsection{Mutual Information Based Methods}

Mutual Information is applied to measure the statistic dependence between the image intensities of corresponding voxels in both images, which is assumed to be maximal if the images are geometrically aligned [14]. It is a measure of how much information one random variable tells about another. For two images, the mutual information is computed from the joint probability distribution of images intensity and gray value. In medical image processing, an application where the alignment is based on images of the same individual is known as intrapatient registration. Matching datasets of different individuals is known as interpatient registration. One of the main advantages of using mutual information is than it can be used to align images of different modalities (e.g. CT to MR-T1, MR-T1 to PET etc).

\subsection{Surface Methods}

It is used for extracting corresponding surfaces in different images and computes the transformation by minimizing some measure of distance between the two surfaces. The surface representation can be simply a point set (i.e., a collection of points on the surface), a faceted surface (e.g., triangle set), an implicit surface, or a parametric surface (e.g., B-spline surface). Surfaces can provide basic features for both rigid body and non rigid registration. Most of the surface based registration algorithms that have been reported are concerned with rigid body transformation $[15-16]$. 


\subsection{Wavelet Based Methods}

The wavelet transform (WT) has gained widespread acceptance in the field of signal processing. The wavelet transform is calculated for each segment according to time at different frequencies. They are particularly suitable for applications where scalability and tolerable degradation are relevant as it is multi-resolution in nature. In Discrete wavelet transform, wavelets are discretely sampled. At each level of decomposition, the signal is split into high frequency and low frequency components. The low frequency can further be decomposed until the desired resolution is achieved. Different types of wavelets like the Haar, Symlet, Daubechies [17] and Coiflets are applied for finding the correspondence with different sets of wavelet coefficients.

\subsection{Correlation Based Methods}

The maximum is searched from the matching or corresponding points obtained from window pairs of sensed and reference images. This is eventually used in multi-modal images and for comparison of various images of similar object or scene [18]. There are two techniques namely Cross - correlation and Phase - correlation based on Fourier transformations are used for image registration. Fourier-based techniques along with search algorithms have been used to estimate the transformation among the two input images [19].

\subsection{Soft Computing Based Methods}

It includes Artificial Neural Networks, Fuzzy Sets and several Optimization Heuristics.

\subsubsection{Artificial Neural Networks}

Artificial Neural Networks are used to process the information the way biological systems process analog signals like image and sound. There are three layers namely Input Layer, Hidden Layer, Output Layer. In Back propagation algorithm, information about errors is filtered back through the system and is used to adjust the connections between the layers, thus improving performance. The algorithm is used to update weights and bias of the neural networks. Weight and bias decides the functionality of the network. Value of the weight and bias elements are calculated during training phase. Neural Networks are used in the medical field for solving mono-modal and multi-modal image registration problems [20].

\subsubsection{Optimization Heuristics}

Optimization Problems may be unconstrained or constrained having both continuous as well as discrete variables. With many limitations being present at the points of global optima the task of finding the optimal solutions is hard. Metaheuristics include Genetic Algorithm (GA) [21], Gravitational Search Algorithm (GSA), Ant Colony Optimization (ACO), Particle Swarm Optimization (PSO) [22], Stimulated Annealing (SA), and Plant Propagation Algorithm (PPA) and so on. These heuristic methods are being used by image registration problems for finding out the best possible parameters necessary for designing a transformation problem [23].

\subsubsection{Fuzzy Sets}

Fuzzy Sets are the extension of conventional (crisp) set theory. It handles the concept of partial truth using a membership function or degrees. It extends conventional Boolean logic to find out partial truths and uncertainties. It is a dominant means to represent and process human understanding in form of fuzzy if-then rules. It is a group of all approaches that understand and process the images, their sections and features are fuzzy sets. This permits Fuzzy sets to deal with vagueness and incorrectness. Fuzzy Sets have been applied in the field of
Medical Image registration also [24].

Summary of Various Image Registration Methods are listed below in Table 1.

Table 1: Presents a summarized view of various Image Registration Methods.

\begin{tabular}{|c|c|c|}
\hline Methods & Key Points & Application \\
\hline $\begin{array}{l}\text { Extrinsic } \\
\text { Methods }\end{array}$ & $\begin{array}{l}\text { External objects or } \\
\text { markers are used in } \\
\text { the patient body to be } \\
\text { registered. }\end{array}$ & $\begin{array}{c}\text { Brain image regis- } \\
\text { tration skin markers } \\
\text { or stereo-tactic } \\
\text { frames. }\end{array}$ \\
\hline $\begin{array}{l}\text { Moments } \\
\text { and Princi- } \\
\text { ple Axes } \\
\text { Methods }\end{array}$ & $\begin{array}{l}\text { It requires the compu- } \\
\text { tation of the centroid } \\
\text { and the three principal } \\
\text { axes for each of the } \\
\text { two scans. }\end{array}$ & $\begin{array}{l}\text { This method is ap- } \\
\text { plied in radiation } \\
\text { treatment planning } \\
\text { based on combined } \\
\text { CT/MR images, in } \\
\text { study of orientation } \\
\text { of the scaphoid bone } \\
\text { in the wrist and in } \\
\text { analyzing PET im- } \\
\text { ages of schizophren- } \\
\text { ics. }\end{array}$ \\
\hline $\begin{array}{l}\text { Mutual In- } \\
\text { formation } \\
\text { Based } \\
\text { Methods }\end{array}$ & $\begin{array}{l}\text { Measures the statistic } \\
\text { dependence between } \\
\text { the image intensities } \\
\text { of corresponding } \\
\text { voxels in both imag- } \\
\text { es, which is assumed } \\
\text { to be maximal if the } \\
\text { images are geometri- } \\
\text { cally aligned. }\end{array}$ & $\begin{array}{l}\text { It is highly reliable } \\
\text { and effective meth- } \\
\text { od of the multimodal } \\
\text { images registration. }\end{array}$ \\
\hline $\begin{array}{l}\text { Surface } \\
\text { Methods }\end{array}$ & $\begin{array}{l}\text { Surface-based image } \\
\text { registration methods } \\
\text { involve determining } \\
\text { corresponding surfac- } \\
\text { es in various images } \\
\text { (and/or physical } \\
\text { space) and computing } \\
\text { the } \\
\text { Transformation that } \\
\text { best aligns these sur- } \\
\text { faces. }\end{array}$ & $\begin{array}{l}\text { Used in Multimodal- } \\
\text { ity Brain image. }\end{array}$ \\
\hline $\begin{array}{l}\text { Wavelet } \\
\text { Based } \\
\text { Methods }\end{array}$ & $\begin{array}{l}\text { It usually extracts a } \\
\text { large number of con- } \\
\text { trol points. The can- } \\
\text { didate control points } \\
\text { are extracted using } \\
\text { the local maxima of } \\
\text { the wavelet coeffi- } \\
\text { cients. }\end{array}$ & $\begin{array}{l}\text { It has been used for } \\
\text { Electrocardiography, } \\
\text { functional neuro- } \\
\text { imaging including } \\
\text { positron emission } \\
\text { tomography and } \\
\text { functional MRI. }\end{array}$ \\
\hline $\begin{array}{c}\text { Correlation } \\
\text { Based } \\
\text { Methods }\end{array}$ & $\begin{array}{l}\text { Eventually used in } \\
\text { multi-modal images } \\
\text { and for comparison of } \\
\text { various images of } \\
\text { similar object or sce- } \\
\text { ne. Extracted features } \\
\text { from the images are } \\
\text { used to obtain the } \\
\text { cross - correlation } \\
\text { coefficients for image } \\
\text { registration. }\end{array}$ & $\begin{array}{l}\text { It has been used to } \\
\text { register tomographic } \\
\text { brain and abdominal } \\
\text { images. }\end{array}$ \\
\hline $\begin{array}{c}\text { Artificial } \\
\text { Neural Net- }\end{array}$ & $\begin{array}{l}\text { It is formulated based } \\
\text { on biological neural }\end{array}$ & $\begin{array}{l}\text { It has been used in } \\
\text { solving mono-modal }\end{array}$ \\
\hline
\end{tabular}




\begin{tabular}{|c|c|c|}
\hline works & networks. & $\begin{array}{c}\text { and multi-modal } \\
\text { medical image regis- } \\
\text { tration problems. }\end{array}$ \\
\hline $\begin{array}{c}\text { Optimization } \\
\text { Heuristics }\end{array}$ & $\begin{array}{c}\text { Genetic Algorithm } \\
\text { (GA) is used to de- } \\
\text { termine which such } \\
\text { features are the most } \\
\text { predictive. }\end{array}$ & $\begin{array}{c}\text { It showed good re- } \\
\text { sults in diagnosing } \\
\text { patient of liver, thy- } \\
\text { roid disorder, and } \\
\text { cancer. }\end{array}$ \\
\hline Fuzzy Sets & $\begin{array}{c}\text { It is a dominant } \\
\text { means to represent } \\
\text { and process human } \\
\text { understanding in form } \\
\text { of fuzzy if-then rules. } \\
\text { This permits Fuzzy } \\
\text { sets to deal with } \\
\text { vagueness and incor- } \\
\text { rectness. }\end{array}$ & $\begin{array}{c}\text { It showed good re- } \\
\text { sults on retinal im- } \\
\text { ages. Bio-medical } \\
\text { images made use of } \\
\text { Neuro fuzzy ap- } \\
\text { proach. }\end{array}$ \\
& & \\
\hline
\end{tabular}

\section{MEDICAL IMAGING APPLICA- TIONS}

For acquiring high resolution and more edifying analysis of human anatomies and its functions becomes possible due to the rapid advances in medical imaging technology. Such development motivates the researchers in the medical image analysis field. Medical Image registration methods can be grouped based on some criterion [25] listed below in Table 2.

Table 2: Classification of Medical Registration Methods

\begin{tabular}{|c|c|c|}
\hline Criteria & $\begin{array}{l}\text { Method- } \\
\text { ologies }\end{array}$ & Examples \\
\hline \multirow{3}{*}{$\begin{array}{l}\text { Dimension- } \\
\text { ality }\end{array}$} & \multirow{3}{*}{$\begin{array}{l}2 D-2 D \\
2 D-3 D \\
3 D-3 D\end{array}$} & $\begin{array}{l}\text { 2D - 2D: registration of } \\
\text { temporal mammograms. }\end{array}$ \\
\hline & & $\begin{array}{l}\text { 3D - 2D: } 3 \mathrm{D} \text { computed to- } \\
\text { mography images and 2D } \\
\text { portal images. }\end{array}$ \\
\hline & & $\begin{array}{l}\text { 3D - 3D: registration of two } \\
\text { tomographic datasets, moni- } \\
\text { toring of tumor growth. }\end{array}$ \\
\hline \multirow{2}{*}{$\begin{array}{l}\text { Domain of } \\
\text { Transfor- } \\
\text { mation }\end{array}$} & Global & $\begin{array}{c}\text { Image of the entire head } \\
\text { based on computation done } \\
\text { in the area of facial surface } \\
\text { only. }\end{array}$ \\
\hline & Local & $\begin{array}{l}\text { Individual vertebrae in an } \\
\text { image of a spinal column. }\end{array}$ \\
\hline \multirow{4}{*}{$\begin{array}{l}\text { Type of } \\
\text { Transfor- } \\
\text { mation }\end{array}$} & Rigid & \multirow{4}{*}{$\begin{array}{c}\text { Head of the same patient, the } \\
\text { skull, falx, tentorium, cardiac } \\
\text { images and postoperative } \\
\text { images etc. }\end{array}$} \\
\hline & Affine & \\
\hline & Projective & \\
\hline & Non Linear & \\
\hline \multirow{2}{*}{$\begin{array}{l}\text { Parameters } \\
\text { of Registra- } \\
\text { tion }\end{array}$} & $\begin{array}{l}\text { Parameters } \\
\text { computed } \\
\text { directly }\end{array}$ & \\
\hline & $\begin{array}{l}\text { Parameters } \\
\text { searched } \\
\text { for }\end{array}$ & \\
\hline \multirow[t]{2}{*}{$\begin{array}{l}\text { Subject of } \\
\text { Registration }\end{array}$} & $\begin{array}{l}\text { Intra sub- } \\
\text { ject }\end{array}$ & \multirow[t]{2}{*}{$\begin{array}{l}\text { 3D / 3D MR or CT brain } \\
\text { image application. }\end{array}$} \\
\hline & Inter sub- & \\
\hline
\end{tabular}

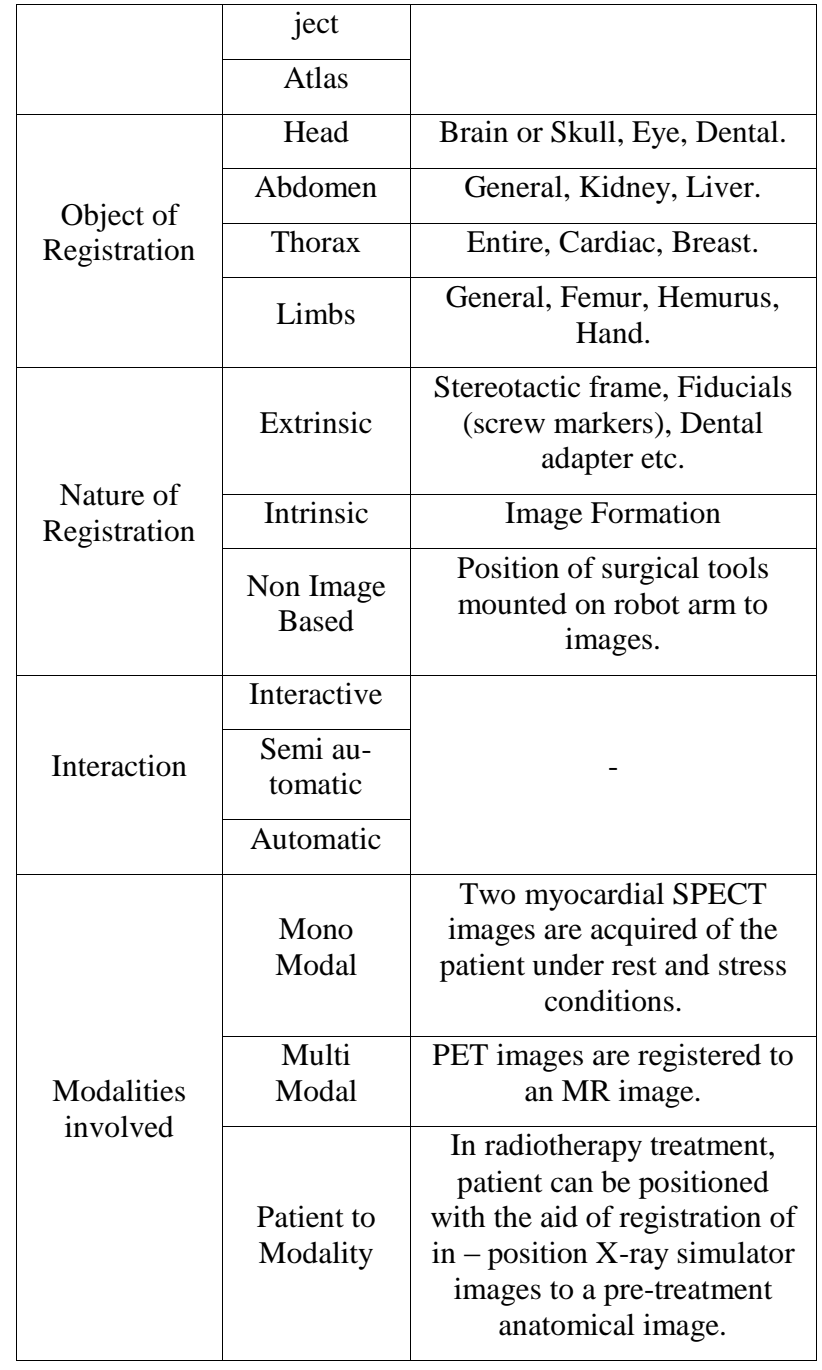

Image Registration Techniques are discussed in the fields of Diabetic Retinopathy and Lesion Detection in Cervix. Other diseases along with its diagnostic modalities used and registration / fusion classes are listed out in Table 3.

\section{DIABETIC RETINOPATHY}

Diabetic Retinopathy is a microvasculature complication of diabetes in retina, causing damage to the blood vessels of the light sensitive tissue at retina, which may also lead to blindness [26]. Eventually due to the increased permeability of the capillary walls, mircroaneurysms along with haemorrhages are formed in retina [27]. As there is an increase of sugar in the blood, it can lead to blockage of the blood vessels which causes microinfarcts called soft exudates in the retina. Clinical signs observed by color fundus photographs include mircroaneurysms, haemorrhages, exudates and intra-retinal micro-vascular abnormalities [26].
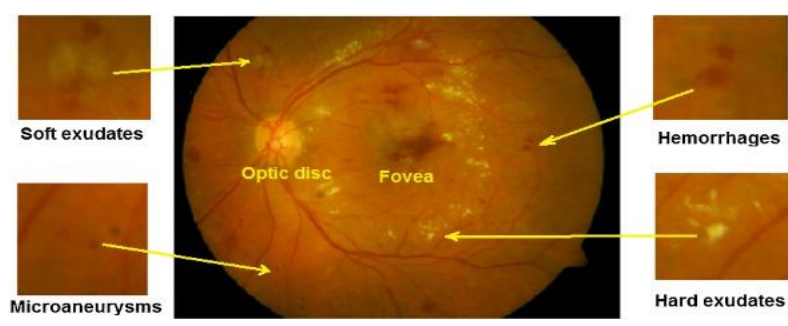

Fig 4: Typical diabetic retinopathy features on a color fundus image. 
Longitudinal Registration method is used to detect and monitor retinal change in Diabetic Retinopathy development and progression. It makes use of Feature based registration methods to extract a set of feature points from each of the reference and floating images, which are then matched to find the transformation. The features are normally vessel structures, branching, bifurcation points, cross-over points etc. which are extracted manually or automatically.

Other Retinal Image Registration methods that are considered are cross-modality registration, spatial registration and temporal registration. When the ophthalmologists wants to use two various imaging modalities to get complementary information about retinal vessel disorder cross-modality registration is considered and when the ophthalmologist's wishes to merge narrow-field images together to produce a wider field view of the retina, spatial registration is considered. The need

Table 3: The current diseases based fusion works

\begin{tabular}{|c|c|c|}
\hline Disease / Disorder/ Surgery & Fusion Classes & Diagnostic Modality \\
\hline \multicolumn{3}{|c|}{ Head } \\
\hline \multirow{2}{*}{$\begin{array}{l}\text { Arterial steno-occlusive disease of the head to } \\
\text { study head motion scanning errors [28] }\end{array}$} & Rigid & \multirow{2}{*}{ PET } \\
\hline & Monomodal & \\
\hline \multirow{2}{*}{ Pituitary adenoma [29] } & Rigid & \multirow{2}{*}{ MR } \\
\hline & Monomodal & \\
\hline \multicolumn{3}{|c|}{ Brain } \\
\hline \multirow{2}{*}{ Huntington's disease [30] } & Nonrigid & \multirow{2}{*}{ MR } \\
\hline & Monomodal & \\
\hline \multirow{2}{*}{ Parkinson's Disease [31] } & Nonrigid + Rigid & MR \\
\hline & Multimodal & SPECT \\
\hline \multicolumn{3}{|c|}{ Eye } \\
\hline \multirow{2}{*}{ Eye fundus (ocular pathologic conditions) [32] } & Rigid & \multirow{2}{*}{ Ophthalmological images } \\
\hline & Multimodal & \\
\hline \multirow{2}{*}{ Retinal diseases [33] } & Rigid & \multirow{2}{*}{ Ophthalmological images } \\
\hline & Multimodal & \\
\hline \multicolumn{3}{|c|}{ Oral } \\
\hline \multirow{2}{*}{ Tongue disorders [34] } & Nonrigid & $\mathrm{hMR}$ \\
\hline & Multimodal & Cine MR \\
\hline \multicolumn{3}{|c|}{ Lung } \\
\hline \multirow{2}{*}{$\begin{array}{l}\text { Assist in detecting and diagnosing lung cancer } \\
\qquad[35]\end{array}$} & Nonrigid & \multirow{2}{*}{ Chest Radiographs } \\
\hline & Monomodal & \\
\hline \multicolumn{3}{|c|}{ Cardiac } \\
\hline \multirow{4}{*}{ Coronary artery diseases [36] } & Rigid & X-ray \\
\hline & Multimodal & $\mathrm{CT}$ \\
\hline & Nonrigid & \multirow{2}{*}{ MR } \\
\hline & Monomodal & \\
\hline \multirow{2}{*}{ Ischemic heart disease [37] } & Rigid + Nonrigid & \multirow{2}{*}{$\mathrm{CT}$} \\
\hline & Monomodal & \\
\hline \multicolumn{3}{|c|}{ Liver } \\
\hline \multirow{2}{*}{ Hepatocellular carcinoma [38] } & Nonrigid & \multirow{2}{*}{$\mathrm{CT}$} \\
\hline & Monomodal & \\
\hline
\end{tabular}

for temporal registration occurs when it is required to track the changes of retina eventually.

\section{LESIONS DETECTION IN CERVIX}

The abnormality found in cervical cells may develop into Cervical Cancer if left untreated. Temporal image registration method is used to detect precancerous lesions of the cervix. The images are obtained from colposcopy examinations. The proposed approach yielded the time series for all pixels in the initial image of the sequence because such values form the basis to establish the similarity. The Temporal method provided the best tradeoff between low error values and time required to carry out the registration process. In addition to it, the temporal method is the most robust among other methods. 
Some of the contributions done in this field along with its best registration / fusion technique are listed out in Table 4.

Table 4: Presents some recent work in medical image fusion for diverse applications

\begin{tabular}{|c|c|c|c|c|c|}
\hline Work & $\begin{array}{c}\text { Fusion Tech- } \\
\text { nique }\end{array}$ & $\begin{array}{l}\text { Level of } \\
\text { Fusion }\end{array}$ & Modality & Organ & Contribution \\
\hline $\begin{array}{l}\text { "Extraction of brain regions } \\
\text { affected by Alzheimer disease } \\
\text { via fusion of brain multispec- } \\
\text { tral MR images" [39]. }\end{array}$ & $\begin{array}{l}\text { Dual tree wave- } \\
\text { let transform } \\
\text { (DTWT) }\end{array}$ & $\begin{array}{l}\text { Pixel } \\
\text { based }\end{array}$ & MRI & Brain & $\begin{array}{l}\text { Proposed a new technique for extrac- } \\
\text { tion of affected regions by Alzheimer } \\
\text { disease from multispectral medical } \\
\text { images by means of fusion and seg- } \\
\text { mentation methods. }\end{array}$ \\
\hline $\begin{array}{l}\text { "Multimodal medical image } \\
\text { fusion using modified fusion } \\
\text { rules and guided filter" [40]. }\end{array}$ & $\begin{array}{l}\text { Gaussian de- } \\
\text { composition, } \\
\text { guided filters, } \\
\text { modified salien- } \\
\text { cy and weight } \\
\text { maps }\end{array}$ & $\begin{array}{l}\text { Window } \\
\text { based }\end{array}$ & MRI & Brain & $\begin{array}{l}\text { Proposed a modified fusion algorithm } \\
\text { to reduce the contrast reduction and } \\
\text { halo artifacts. }\end{array}$ \\
\hline $\begin{array}{c}\text { "Multimodal medical image } \\
\text { sensor fusion framework using } \\
\text { cascade of wavelet and } \\
\text { contourlet transform domains" } \\
\text { [41] }\end{array}$ & PCA & $\begin{array}{l}\text { Pixel } \\
\text { based }\end{array}$ & MRI, CT & Brain & $\begin{array}{l}\text { Proposed a multimodal fusion algo- } \\
\text { rithm that consists of two stages: } \\
\text { stationary wavelet transform (SWT) } \\
\text { and non sub-sampled contourlet } \\
\text { transform (NCST) to enhance the } \\
\text { shift variance, directionality and } \\
\text { phase information. }\end{array}$ \\
\hline $\begin{array}{l}\text { "Medical image fusion by } \\
\text { combining SVD and shearlet } \\
\text { transform" [42]. }\end{array}$ & $\begin{array}{l}\text { Maximum fu- } \\
\text { sion rule }\end{array}$ & $\begin{array}{l}\text { Pixel } \\
\text { based }\end{array}$ & MRI, PET & Brain & $\begin{array}{l}\text { Proposed a two stage fusion tech- } \\
\text { nique using shearlet transform and } \\
\text { then applying SVD on low pass sub- } \\
\text { bands before fusion to provide higher } \\
\text { image quality. }\end{array}$ \\
\hline $\begin{array}{l}\text { "Free-breathing diffusion ten- } \\
\text { sor imaging and tractography } \\
\text { of the human heart in healthy } \\
\text { volunteers using wavelet based } \\
\text { image fusion" [43]. }\end{array}$ & $\begin{array}{l}\text { Wavelet based } \\
\text { image fusion } \\
\text { algorithm }\end{array}$ & $\begin{array}{l}\text { Window } \\
\text { based }\end{array}$ & $\begin{array}{l}\text { Diffusion } \\
\text { Tensor } \\
\text { Imag- } \\
\text { ing(DTI) }\end{array}$ & Heart & $\begin{array}{c}\text { Proposed a technique to provide } 3 \mathrm{D} \\
\text { fiber architecture properties of the } \\
\text { human heart. }\end{array}$ \\
\hline $\begin{array}{l}\text { "Spine medical image fusion } \\
\text { using wiener filters in shearlet } \\
\text { domain" [44]. }\end{array}$ & $\begin{array}{l}\text { Maximum fu- } \\
\text { sion rule }\end{array}$ & $\begin{array}{l}\text { Pixel } \\
\text { based }\end{array}$ & MRI, CT & Spine & $\begin{array}{l}\text { Proposed an algorithm that provides } \\
\text { both functional and anatomical struc- } \\
\text { ture for spine by applying three steps: } \\
\text { Shearlet transform, Wiener filter, } \\
\text { Fusion of low and high pass sub } \\
\text { bands. }\end{array}$ \\
\hline $\begin{array}{l}\text { "Multi focus and multi modal } \\
\text { image fusion using wavelet } \\
\text { transform" [45]. }\end{array}$ & $\begin{array}{c}\text { Dual tree dis- } \\
\text { crete wavelet } \\
\text { transform(DT- } \\
\text { DWT) }\end{array}$ & $\begin{array}{l}\text { Pixel } \\
\text { based }\end{array}$ & MRI, CT & Brain & $\begin{array}{l}\text { Proposed a multifocus and multimod- } \\
\text { al image fusion techniques using DT- } \\
\text { DWT then applying fuzzy logic clus- } \\
\text { tering for segmentation that helps in } \\
\text { tumor identification. }\end{array}$ \\
\hline
\end{tabular}

\section{CONCLUSION}

To extract information from different images which comes from different sources, Image Registration plays a crucial role. This paper presented a survey on various Image Registration methods as well as Medical Image Registration and/or fusion. Fundamentals of Image Registration methods and techniques were discussed followed by the application areas where it is used. Objective of Image Registration is to combine two or more images and extract information from them. Then a discussion for Medical Imaging Modalities and the Medical Image Registration was been done. In today's context, Medical Image Registration is considered relevant for the medical experts to make decisions regarding the patient's condition. This paper also covers some recent contribution of Medical Image fusion for diverse applications.

\section{REFERENCES}

[1] Manjusha Deshmukh, Udhav Bhosle "A survey of image registration", "International Journal of Image Processing (IJIP), Volume (5): Issue (3), 2011".

[2] D.L.G. Hill, P.G. Batchelor, M. Holden, D.J. Hawkes, Medical image registration, Physics in Medicine and Biology 46 (2001) R1-R45.

[3] H. Lester, S.R. Arridge, A survey of hierarchical nonlinear medical image registration, Pattern Recognition 32 (1999) 129-149.

[4] P.A. van den Elsen, E.-J.D. Pol, M.A. Viergever, Medical image matching-a review with classification, IEEE Engineering in Medicine and Biology 12 (1993) 26-39.

[5] J.B.A. Maintz, M.A. Viergever, A survey of medical 
image registration, Medical Image Analysis 2 (1998) 136.

[6] Damas, Sergio, Oscar Cordón, and Jose Santamaría. "Medical image registration using evolutionary computation: An experimental survey." IEEE Computational Intelligence Magazine 6.4 (2011): 26-42.

[7] Barbara Zitova, Jan Flusser "A survey on image registration methods", "Image and vision computing 21(2003) 977-1000".

[8] Alexander Wong, David A. Clausi "ARRSI: Automatic Registration of Remote-Sensing Images", " IEEE Transactions on Geoscience and Remote Sensing, volume(45), No. 5, May 2007".

[9] K. P. Gall and L. J. Verhey, "Computer-assisted positioning of radiotherapy patients using implanted radioopaque fiducials", Medical physics, 1993, 11521159.

[10] C. R. Maurer, G. B. Aboutanos, B. M. Dawant, R. A. Margolin, R. J. Maciunas and J. M. Fitzpatrick., "Registration of CT and MR brain images using a combination of points and surfaces", Medical imaging: image processing, volume 2434, Bellingham, WA, 1995. SPIE Press, 109-123.

[11] A. C. Evans, S. Marrett, J. Torrescorzo, S. Ku, and L.Collins, "MRI-PET correlation in three dimensions using a volume of interest (VOI) atlas", Journal of cerebral blood flow and metabolism , 11, A69-A78, 1991.

[12] W. D. Leslie, A. Borys, D. McDonald, J. O. Dupont and A. E. Peterdy, "External reference markers for the correction of head rotation in brain single-photon emission tomography", European journal of nuclear medicine, 22(4):351-355, 1995.

[13] J. Flusser, T. Suk, A moment-based approach to registration of images with affine geometric distortion, IEEE Transactions on Geoscience and Remote Sensing 32 (1994) 382-387.

[14] P.Viola, W.M. Wells, "Alignment by maximization of mutual information", International Journal of Computer Vision 24, (1997), 137-154.

[15] S.M. Yamany, A.A. Farag, "Free-form surface registration using surface signatures" Proceedings of the Seventh IEEE International Conference on Computer Vision, Vol. 2, 1999, 1098-1104.

[16] Chi Kin Chow, Hung Tat Tsui, Tong Lee, "Surface registration using a dynamic genetic algorithm", Pattern Recognition 37, (2004), 105-117.

[17] J. le Moigne, "Parallel registration of multi-sensor remotely sensed imagery using wavelet coefficients", Proceedings of the SPIE: Wavelet Applications, Orlando, Florida, 2242, (1994), 432-443.

[18] B.K. Ghaffary, A.A. Sawchuk, "A survey of new techniques for image registration and mapping", Proceedings of the SPIE: Applications of Digital Image Processing 432 (1983) 222-239.

[19] Samritjiarapon O. Chitsobhuk O. , "An FFT-Based Technique and Best-first Search for Image Registration", International Symposium on Communications and Information Technologies, ISCIT 2008.
[20] Lifeng Shang, Jian Cheng Lv, Zhang Yi, "Rigid medical image registration using PCA neural network", Neurocomputing 69 (2006), 1717-1722.

[21] S.-J. Wu and P.-T. Chow, Genetic algorithms for nonlinear mixed discrete-integer optimization problems via meta-genetic parameter optimization, Engineering Optimization, vol. 24, no. 2, pp. 137-159, 1995.

[22] R. Eberhart and J. Kennedy, A new optimizer using particle swarm theory, in Proceedings of the 6th International Symposium on Micro Machine and Human Science (MHS '95), pp. 39- 43, IEEE, Nagoya, Japan, October 1995.

[23] J.M. Rouet, J.J. Jacq, and C. Roux, "Genetic algorithms for a robust 3-D MR-CT registration," IEEE Trans. Inform. Technol. Biomed., vol. 4, (Jun. 2000), 126-136.

[24] Ramirez L. Durdle N.G. Raso V.J. "A Parameters Selection Scheme for Medical Image Registration", Fuzzy Information Processing Society, 2006. NAFIPS 2006. Annual meeting of the North American (June2006), 505510.

[25] J. B. Antoine Maintz and Max A. Viergever "An overview of medical image registration methods", "August 1998 UUCS-1998-22 ISSN: 0924-3275".

[26] H. Narasimha-Iyer, C. Ali, R. Badrinath, V.S. Charles, et al.Robust detection and classification of longitudinal changes in color retinal fundus images for monitoring diabetic retinopathy IEEE Trans. Biomed. Eng., 53 (6) (2006), pp. 1084-1098.

[27] T. Kauppi, V. Kalesnykiene, J.K. Kamarainen, et al.Diaretdb1 diabetic retinopathy database and evaluation protocol Medical Image Understanding and Analysis (MIUA' 07)(2007), pp. 61-65.

[28] Matsubara K, Ibaraki M, Nakamura K, Yamaguchi H, Umetsu A, Kinoshita F, et al. Impact of subject head motion on quantitative brain $15 \mathrm{O}$ PET and its correction by image-based registration algorithm. Ann Nucl Med 2013; 27(4):335-45.

[29] Ringstad G, Emblem K, Holland D, Dale A, Bjornerud A, Hald J. Assessment of pituitary adenoma volumetric change using longitudinal MR image registration. Neuroradiology 2011; 54():435-43.

[30] Modat M, Taylor Z, Ridgway G, Barnes J, Wild E, Hawkes D, et al. Nonlinear elastic spline registration: evaluation with longitudinal Huntington's disease data. In: Biomedical image registration; 2010. p. 128-39.

[31] Lee J, Huang C, Chen C, Weng Y, Lin K, Chen C. A brain MRI/SPECT registration system using an adaptive similarity metric: application on the evaluation of Parkinson's disease. In: Computer vision/computer graphics collaboration techniques; 2007. p. 235-46.

[32] Bernardes R, Guimaraes P, Rodrigues P, Serranho P. Fully-automatic multimodal co-registration of retinal fundus images.In: IFMBE proceedings; 2014. p. 248-51.

[33] Ghassabi Z, Shanbehzadeh J, Sedaghat A, Fatemizadeh E. An efficient approach for robust multimodal retinal image registration based on UR-SIFT features and PIIFD descriptors.EURASIP J Image Video Process 2013; 2013(1):25.

[34] Woo J, Stone M, Prince J. Deformable registration of 
high-resolution and Cine MR tongue images. Lect Notes Comput Sci 2011:556-63.

[35] Li M, Castillo E, Luo H, Zheng X, Castillo R, Meshkov $\mathrm{D}$, et al.Deformable image registration for temporal subtraction of chest radiographs. Int J CARS 2013; 9(4):513-22.

[36] Moosavi Tayebi R, Wirza R, Sulaiman P, Dimon M, Khalid F,Al-Surmi A, et al. 3D multimodal cardiac data reconstruction using angiography and computerized tomographic angiography registration. $\mathrm{J}$ Cardiothorac Surg 2015; 10(1):1-25.

[37] Zuluaga M, Hernandez Hoyos M, Davila J, Uriza L, Orkisz M. A fast lesion registration to assist coronary heart disease diagnosis in CTA images. In: Computer vision and graphics; 2012. p. 710-7.

[38] Xu H, Gong G, Wei H, Chen L, Chen J, Lu J, et al. Feasibility and potential benefits of defining the internal gross tumor volume of hepatocellular carcinoma using contrast-enhanced 4D CT images obtained by deformable registration. Radiat Oncol2014; 9(1):221.

[39] Tannaz Akbarpour, Mousa Shamsi, "Extraction of Brain Regions Affected by Alzheimer Disease Via Fusion of Brain Multispectral MR Images", International Conference on Information and Knowledge Technology, pp. 16,2015 .
[40] Pritika, Sumit Budhiraja, "Multimodal Medical Image Fusion Using Modified Fusion Rules and Guided Filter", International Conference on Computing, Communication and Automation (ICCCA), pp. 1067-1072, ISBN 978-14799-8889-1, 2015.

[41] Vikrant Bhateja, Aimé Lay-Ekuakille, "Multimodal Medical Image Sensor Fusion Framework Using Cascade of Wavelet and Contourlet Transform Domains", IEEE Sensors Journal, vol. 15, no. 12, December 2015.

[42] Biswajit Biswas, Somoballi Ghoshal, "Medical Image Fusion by Combining SVD and Shearlet Transform", 2nd International Conference on Signal Processing and Integrated Networks (SPIN), 2015.

[43] Hongjiang Wei, Magalie Viallon, "Free-Breathing Diffusion Tensor Imaging and Tractography of the Human Heart in Healthy Volunteers Using Wavelet-Based Image Fusion", IEEE Transactions on Medical Imaging, Vol. 34, No. 1, January 2015.

[44] Biswajit Biswas, Amlan Chakrabarti, "Spine Medical Image Fusion Using Wiener Filter in Shearlet Domain", IEEE 2nd International Conference on Recent Trends in Information Systems, 2015.

[45] Vani M, Saravanakumar S, "Multi Focus and MultiModal Image Fusion Using Wavelet Transform", 3rd International Conference on Signal Processing, Communication and Networking (ICSCN), 2015. 